\title{
Stakeholder Networks and Strategy: The Influence of Network Consistency and Network Diversity on Firm Performance
}

\author{
Richard Peters \\ Xavier University of Louisiana • New Orleans, Louisiana \\ Peggy Golden \\ Florida Atlantic University • Boca Raton, Florida
}

\section{ABSTRACT}

As academic and practitioners continue to demand greater stakeholder acknowledgement and engagement, firms must seek ways to move beyond dyadic interactions and treat internal and external stakeholders as components of a holistic network. This paper introduces two new constructs, Network Diversity and Network Consistency, proposing that both the variety of stakeholder partners (Network Diversity) as well as the uniformity of social performance across multiple stakeholder constituencies (Network Consistency), will influence Corporate Reputation (CR) and ultimately, firm financial performance. Using a sample of 158 firms, across a five year time span,we find that while Network Diversity has no significant relationship to CR, Network Consistency is in fact related to Corporate Reputation. Further, high levels of Network Diversity may actually detract from, rather than enhance financial performance, via increased cost and relationship management complexity.

\section{INTRODUCTION}

The concept of Corporate Reputation, and its relationship to firm performance, is not novel to business literature. Academics have written extensively and even previously tested this link, indicating that there is both theoretical and empirical evidence supporting the strategic benefit of a superior CR.

Yet, despite this previous work, less emphasis has been placed upon identifying the antecedents of CR and how they can best be used to enhance financial outcomes. To address this deficiency, we address two specific questions: (1) How can the firm's CR, or what we will soon refer to as its reputational stock, be increased, and (2) How can the firm's approach to stakeholder management attenuate the relationship between its reputation and financial performance.

Exploration of these two issues requires richer understanding of the underpinnings of Corporate Reputations. Generally, most authors agree that corporate reputa- 
tions emerge from the evaluations stakeholders (both internal and external), ascribe to the firm (Barnett, 2007). Two important characteristics of these evaluations may help illuminate the nature and antecedents of firm reputations.

First, these evaluations are based upon the firm's behavior, both intentional and unintentional, towards its various stakeholder constituents (Fombrun \& Shanley, 1990; Fombrun, 1996). Thus the firm's ability to effectively manage and mets ts stakeholder obligations is likely to positively influence evaluations (Russo \& Fouts, 1997; Hillman \& Keim, 2001) and enhance the firm's CR (Fombrun, 1996; Fombrun et al. 2000). Second, while individual stakeholders provide separate evaluations; "sub-reputations" (Neville, Bell \& Mengue, 2005: 1189), the firm's overall Corporate Reputation is essentially a collection and/or integration of these individualized assessments (Fombrun, 1996; Weiss, Anderson \& MacInnis, 1999; Hutton, Goodman, Alexander \& Genest, 2001; Neville et al. 2005, Barnett, 2007).

Thus, it is clear that a firm's CR is a function of both its individual and collective stakeholder performance and that a network approach to stakeholder management is essential to explaining the firm's reputational 'drivers'. A stakeholder network approach, unlike a dyadic treatment of firm-stakeholder interaction, simultaneously accounts for both individual as well as structural ties. It acknowledges that while specific firm-stakeholder ties provide firms with opportunities and constraints, the assimilation and integration of these ties create an holistic network structure, that can impact, if or how the firm derives and/or benefits CR (Granovetter, 1992; Gulati \& Gargiulo, 1999; Borgatti \& Foster, 2003).

Consistent with this stakeholder network approach, two concepts, Network Diversity and Network Consistency, are introduced. Network Diversity refers to the number of distinct stakeholder relationships the firm adopts and implements. Network Consistency, on the other hand, considers the uniformity of social performance across multiple stakeholder relationships.

We propose that these constructs will have both a direct relationship to CR as well as a moderating effect on the relationship between CR and firm financial performance. The former effect is premised on the ability of these constructs to foster greater and more positive flows of reputational equity from firm stakeholders. Positive and continuous flows lead to an accumulated stock of intangible, but valuable Corporate Reputation. ${ }^{1}$ The latter effect suggests that CRs, built on high Network 
Diversity and consistency, are inherently complex and thus difficult to imitate. Complex resources are difficult to imitate since they not only require identification of the specific resource elements, but also the successful replication and management of the interdependencies among these elements (Black \& Boal, 1994). This makes these types of CRs more valuable and rare (Barney, 1991); therefore more likely to contribute to positive financial outcomes.

The rest of our paper is dedicated to theoretically and empirically examining these two general effects (direct and moderating). The following sections provide our hypothesis development. We then present our findings and lastly discuss their implications to our research and possible future study.

\section{THEORETICAL FRAMEWORK}

Figures 1 and 2 illustrate our proposed models and their underlying effects. As argued above, Network Diversity and Network Consistency, affect corporate reputation in two distinct ways. First, as illustrated in Figure 1, we propose that they help firms increase their overall stock of CR, and are thus direct antecedents. Second, as shown in Figure 2, because of their proposed ability to promote CR complexity, rareness and inimitability, both constructs are hypothesized to moderate the relationship between $\mathrm{CR}$ and firm financial performance.

Figure 1

\section{Direct Model}

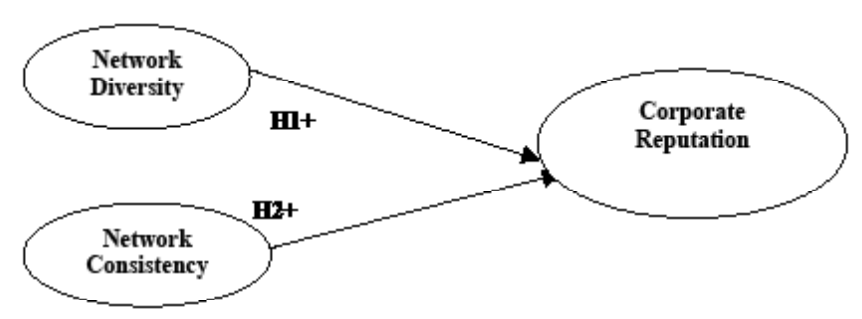


Figure 2

Moderator Model

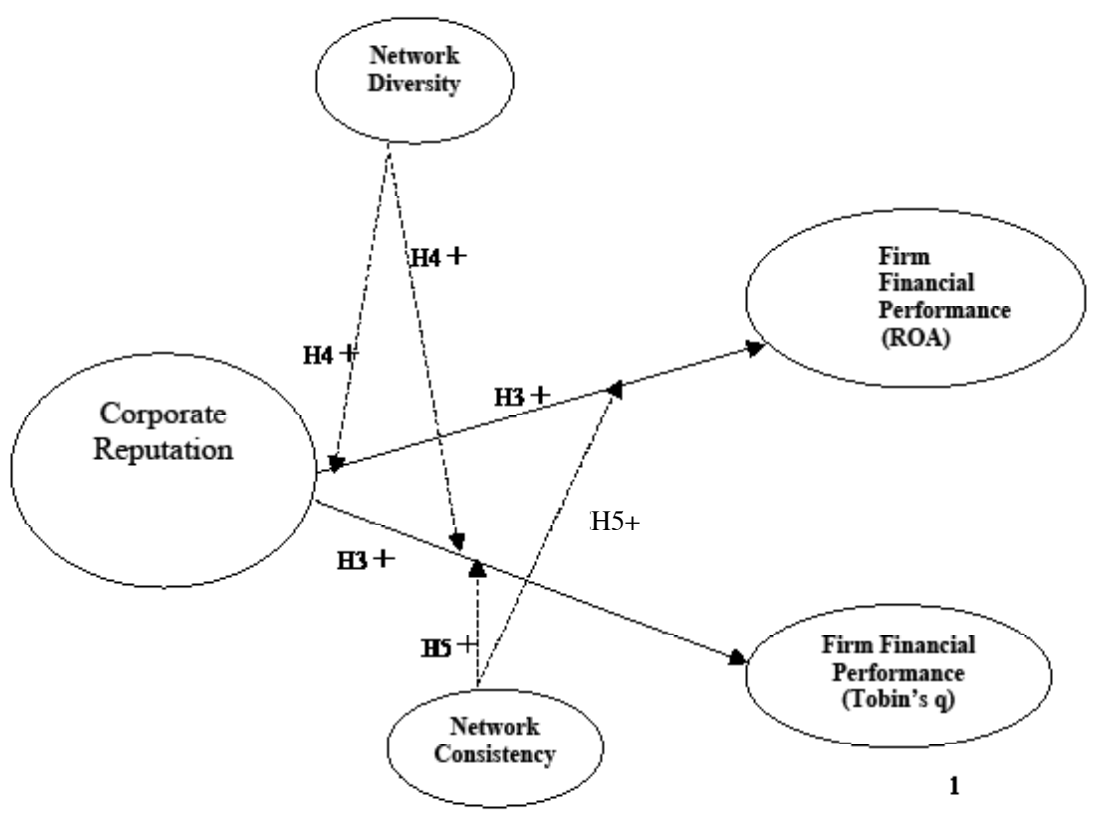

HYPOTHESIS DEVELOPMENT

\section{Network Diversity-Corporate Reputation}

The concept of Network Diversity is similar, but not equivalent, to conventional network constructs such as size and density. As with network size and density, Network Diversity is dependent on the number of actors and relationships present throughout the entire system. Unlike size and density, however, Network Diversity is also contingent upon the level of diversity among network members. While a firm can increase its stakeholder network size by engaging in additional individual stakeholder relationships, it can only improve its Network Diversity by adopting additional stakeholder group relationships. Therefore a firm that maintains relationships with customers, employees and environmental activists is argued to demonstrate more Network Diversity than one that has a strong relationship with only its customer base. Fiji Water working with environmental groups or Wal-Mart engaging with community agencies indicate tangible examples of firms increasing their Network Diversity by adding new stakeholder 'types' instead of stakeholder 'numbers'. 
Network Diversity is argued to positively affect CR by increasing its overall stock of firm reputation capital. Similar to Fombrun and Shanley (1990) and Bromley (2000), we argue that each new stakeholder group represents a potentially unique contributor to CR, and thus an additional and distinct flow towards overall CR stock. As Network Diversity increases, the firm's number of potential avenues from which to 'draw' positive CR increases. Therefore a firm is able to decisively leverage its reputation for strategic gain. Today, for example, we might expect Network Diversity to extend itself to suppliers or vendors such as recycling agencies with waste management.

While it is arguable that the firm can create a similar effect, (i.e. increase its reputation stock), by simply increasing the numbers of relationships within existing stakeholder constituencies (for example working with more community groups or environmental NGOs), we suggest that the incremental contribution to CR of a new stakeholder from a previously unaffiliated stakeholder constituency is greater than that of a new partner in an already affiliated constituency. Thus, we propose that scope is better than size, a position consistent with Granovetter's weak ties argument. Granovetter (1973) proposes that individuals were more likely to get valuable job leads through persons outside their 'social inner circles', since the information garnered from these immediate social circles was often myopic, subjectively biased, and relatively common. Thus, by increasing their Network Diversity, an individual could access, not only greater, but also more unique sources of information, which proved advantageous to their employment searches.

Similarly, firms, which extend their stakeholder networks to include new stakeholder constituencies, are expected to mitigate the redundancy that comes from network homogeneity, and capitalize on the unique contribution each new constituency provides to CR stock. Therefore, Network Diversity is expected to positively impact the corporate social reputation the firm achieves through its CSR initiatives.

H1: Network Diversity is positively related to Corporate Reputation Network Consistency-Corporate Reputation

Another stakeholder network attribute that is argued to influence the magnitude of CR stock is Network Consistency. Network Consistency is a measure of uniformity, or conversely variance, in the firm's social performance across its multiple stakeholder constituencies. High Network Consistency occurs when there is minimal discrepancy in the firm's positive treatment of its stakeholder constituencies across the entire stakeholder network. Conversely, low Network Consistency, occurs when the firm excessively discriminates among its stakeholder constituents, 
treating some significantly better or worse than others. An example might be deference to union negotiations at a high cost in an austere financial climate.

While stakeholder groups (constituencies) are expected to concentrate mainly on their own expectation and needs when evaluating firms, they may also consider firm treatment of other stakeholders when determining firm reputation. For example, Brown and Dacin (1997) show that customers may consider employee well-being when making purchasing decisions. Further, Turban and Greening (1997) propose that firm CSR, in some cases, matter to prospective employees. Employee well-being is generally translated into satisfied customers.

As stakeholders become aware and interested in the welfare of others outside their primary stakeholder constituency, a firm's holistic performance across its stakeholder network becomes significantly important to its CR stock. Certain factors within the stakeholder network and general environment, such as role multiplicity and media intervention, increase the propensity of stakeholders within one constituency to consider those in another. With respect to role multiplicity, almost everyone in society performs multiple roles in order to fulfill diverse personal, professional and social needs (Beggs, Haines \& Hurlbert, 1996). As no single social institution can fulfill all human need, individuals must often subscribe to multiple social groups. Role multiplicity presumes that individuals, by virtue of their different social roles, can potentially hold dual or multiple stakeholder constituent membership. Customers can simultaneously be environmental activists, while employees might act as community leaders.

These simultaneous roles allow these stakeholders to observe the firm's actions in different contexts, and thereby evaluate the firm's consistency across multiple stakeholder domains. Additionally, stakeholders belonging to more than one stakeholder constituency may act as boundary spanners. Boundary spanners are internal sources of external information (Kostova \& Roth, 2003). They introduce 'in-group' members to the attitudes, experiences and needs of 'outsiders'. Because of their primary knowledge about firm behavior and their ties to multiple stakeholder constituents, these boundary spanners increase awareness of firm inconsistency across large sections and in some instances, the entire stakeholder network.

The external media also provides an avenue through which stakeholders can acquire information about Network Consistency. Because of the recent ethical fiascos, such as Nike's sweat-shop labor problems in Asia, Enron's fraudulent accounting, and WorldCom's mismanagement issues, the social responsiveness has been subjected to the popular press as well as academia. The information reported in academic journals, daily periodicals, business publications and television, provide 
stakeholders with a clearer image of the firm's overall character, which then allows them (stakeholders) to evaluate the firm's Network Consistency.

By acting inconsistently across their stakeholder networks, firms risk eroding their established stock of CR. Stakeholders that are both aware of and concerned with the firm's performance across multiple stakeholder constituencies are likely to react less favorably to low Network Consistency. For example, an employee who is treated well by his/her respective organization is likely to have a favorable impression of the firm. This impression, however, might be severely tainted if this employee lived in the community in which the firm operated in, and experienced the firm's pollution first-hand. Similarly, a customer who is appreciative of the company's provision of highly innovative products may become less enamored with the firm upon learning that these products are manufactured using sweat-shop labor.

Even for stakeholders that are not unduly concerned with the welfare of others outside their immediate stakeholder constituency, Network Consistency can still be a factor in determining CR. Individuals utilize information about the firm's behavior from multiple stakeholder sources, including themselves, to assess the organization's credibility (Whetten \& Mackey, 2002; Neville et al., 2005). If these multiple sources are incongruent, stakeholders become less willing to trust the organization and ascribe to it a positive CR (Lewis, 2003).

H2: Network Consistency is positively related to Corporate Reputation

\section{Corporate Reputation and Financial Performance}

The instrumental value of CR to the firm is demonstrated in its effect on both organizational efficiency and product differentiation (Roberts \& Dowling, 2002). These two advantages help the firm to reduce its organizational costs (via organizational efficiency) and distinguish itself in the marketplace (via differentiation). These can separately, and in tandem, lead to positive financial outcomes.

Positive and superior CRs are often built upon constructive and dedicated stakeholder-firm relationships. These relationships are characterized by increased levels of dedication, personalization and trust (Hillman \& Keim, 2001). The firm, by actively and consistently addressing the needs of its stakeholder, engenders not only positive stakeholder perceptions but also a distinct atmosphere of reciprocity, wherein stakeholders feel socially and personally obligated to tangibly reward the firm. The reward results in a willingness on the part of stakeholders, such as employees (Turban \& Greening, 1997), investors (Srivastava, McInish, Wood \& Capraro, 
1997), suppliers and governments (Fombrun, 1996; Fombrun et al., 2000) to grant the firm greater access to the resources they own (knowledge, capital, raw materials, legitimacy etc.). The increased investments in Socially Responsible funds are arguably a testament of this 'efficiency' effect (c.f. US SIF Report 2012). Firms are in competition for these resources and, easier and/or greater access can significantly help promote organizational efficiency, and financial performance (Hart, 1995; Nelson \&Winter, 1982, Eisenhardt \& Martin, 2000; Helfat \& Peteraf, 2003).

Differentiation, much like organizational efficiency, allows the firm to improve its financial performance as well as achieve a competitive advantage over its existing industry rivals (Barney, 1991; Porter, 1985 \& 1996). The instrumentality of differentiation stems from the value customers place on unique firm and product attributes which increases their propensity to purchase as well as their willingness to pay higher prices for products they deem to be differentiated.

Previous researchers have argued, and in some cases demonstrated a positive link between CR and customer-related performance indicators (Sanchez \& Sotorrio, 2007). For example, Carmeli and Tishler (2005), using a sample of 300 kibbutz enterprises, found a positive relationship between reputation and amount of customer orders. Walsh, Dinnie and Weidmann, (2006) demonstrate that CR and customer satisfaction are positively correlated, from their sample of 422 customers of a German utility firm. With respect to buying intention, Yoon, Guffie and Kijewski (1993) show that customers were more willing to purchase business services from companies deemed to be reputable. And in terms of pricing, Shapiro (1983) empirically demonstrates that customers are motivated to pay more for products from firms that have reputations for high quality manufacturing.

These findings suggest that along with improved efficiency, a superior CR can help firms differentiate themselves and their product/services in the marketplace. H3: Corporate Reputation is positively related to Firm Financial Performance

\section{MODERATING EFFECT ON CR-FIRM FINANCIAL PERFOR- MANCE}

\section{Network Diversity}

Our underlying argument for a moderating effect, by both Network Diversity and Network Consistency, on the relationship between CR and Firm Financial Performance, rests on the proposed ability of these two network constructs to increase 
CR complexity and inimitability. As others have suggested (Roberts \& Dowling, 2002; Bronn \& Bronn, 2005), CR, because of its intangible nature, is complex and often multifaceted, and thus difficult to imitate. This ambiguity and inimitability are reasons it can serve as a firm distinctive competency (Roberts \& Dowling, 2002). Congruently, we propose that any effect that can either increase or decrease this complexity and inimitability will likely alter the financial benefit of the firm's CR, and will thus act to moderate this direct relationship.

As argued previously, by increasing Network Diversity, the firm gains reputational flows from multiple and importantly, unique sources. These unique sources are not just simply 'more tributaries in the river of CR stock', but potential inhibitors to $\mathrm{CR}$ imitation. Since each firm-stakeholder constituent network tie represents a substantial investment of time, resources, capital and human acumen (Stanwick \& Stanwick, 1998), increasing Network Diversity may make CR imitation financially prohibitive for competitors.

Further, because of heterogeneity present in diverse stakeholder networks, potential imitators must invest in multiple, differentiated skills, technology and knowledge to be successful at complete CR imitation. Neville et al. (2005) suggest that each stakeholder group is idiosyncratic with respect to their needs and demands on the firm. To simultaneously maintain stakeholder group relationships, firms must effectively fulfill these differentiated needs and demand, which often requires diverse sets of resources and skills. This then represents an additional obstacle or to potential imitators and thus further protects the strategic value of firm's CR.

H4: Network Diversity moderates the relationship between Corporate Reputation and Firm Financial Performance

\section{NETWORK CONSISTENCY}

Network Consistency also provides implications for CR complexity and inimitability. Firms, which behave consistently across their stakeholder networks (high Network Consistency), it can be argued, demonstrate an understanding of the dynamic interdependencies across their multiple stakeholder constituencies. Using a river analogy, while it is relatively easy to identify each tributary before it meets the river, once entry occurs, it is practically impossible to isolate its individual contribution. Similarly, as stakeholder groups and their interests coalesce and become interconnected, the ability of potential imitators to discern the sources of CR, as well as their effect on firm profitability is severely precluded. Thus, firms familiar with stakeholder independencies, and the ability to successfully leverage them, are 
advantageously positioned relative to their present and would-be competitors, and are likely to reap the financial benefits of positive and superior CRs.

H5: Network Consistency moderates the relationship between Corporate Reputation and Firm Financial Performance

\section{METHODOLOGY}

\section{Sample}

Data for one hundred and fifty eight companies, across multiple industries, over a five-year period were collected, pooled and analyzed. This resulted in seven hundred and ninety observations (790) for each construct. The companies chosen are U.S. firms, which cover a variety of industries including travel, retailing, telecommunications, energy and health care. While all constructs were measured over five years, the specific five -year period differed across constructs. For Firm Financial Performance, the construct was measured from 1995 to 1999, for Corporate Reputation from 1994 to 1998, and for Network Diversity and Network Consistency from 1993 to 1997. This variation in five-year period was a consequence of lagging independent variables one year, relative to their respective dependent variable.

The time period, 1995-1999, was selected based on the matched availability and completeness of construct information across the three main sources of secondary data: the Kinder, Lindenberg \& Domini (KLD) ratings, the Fortune Most Admired Companies annual rankings and the Compustat database. It should be noted that companies for which there was missing data from the Reputation or Compustat databes were kept only if there was available data for at least three years on each measure. The missing data was imputed based on the average of the known data for that firm, for that particular construct. Importantly, the number of firms for which there was any missing data for any construct was always small relative to the overall sample, never exceeding more than eighteen firms.

\section{MEASURES}

Corporate Reputation (CR) With the recent surge in research dedicated to Corporate Social Reputation, issues related to conceptualizing and measuring this complex construct have emerged at the forefront of this niche area of business study (Money \& Hillenbrand, 2006). Numerous measures including the Reputation Quotient (RQ) (Fombrun, 1996), Corporate Personality Scale (Davies et al., 2003), and 
the SPIRIT instrument (McMillan et al., 2004) have been created and used to operationalize Corporate Social Reputation. While these measures individually offer great conceptual and empirical insight into both the antecedents and consequences of Corporate Reputations, their newness, data unavailability and lack of widespread use make them relatively inappropriate for this type of longitudinal, strategic study.

One instrument that has a historical legacy, widespread application, and considerable acceptance in the academic arena is the Fortune Most Admired Company Rankings (Luo \& Bhattacharya, 2006; Roberts \& Dowling, 2002). Since 1983, the Fortune periodical has published a list of the most admired companies in the United States. In order to develop and publish these lists, Fortune surveys multiple managers, across various industries, as well as strategic and financial analysts possessing intimate industry and firm knowledge. Variables within the Fortune instrument evaluate firm behavior, ability, and performance on eight dimensions including innovation, financial well-being, product quality, trust, community involvement, sustainability, consumerism and employee management (Luo \& Bhattacharya, 2006). Overall reputation scores are the average of the scores on all eight dimensions, which are each scaled from 1-10, (one being the least reputable and ten the most).

While reputation data for the majority of firms in the final sample was complete (i.e. scores were retrieved for all five years between 1994 and 1998), eighteen firms had missing reputation scores for at least one year but not more than two years. In order for these firms to be accepted into the final sample they must have had a recorded reputation score for the first year (1994) and also demonstrate reputation scores for three consecutive years. To impute the missing values, a moving average (prior or post) was calculated, based on the available reputation scores and substituted for the missing data point. This method seemed suitable considering the fact that reputation scores across a moderate period of time are relatively stable and consistent (Luo \& Bhattacharya, 2006); thus, previous or even future reputation scores could be credibly used to impute missing data. Also, as this imputation was done for only a small portion of the sample (eighteen firms) any potential negative effects on empirical validity were relatively minimized in a total sample of 158 .

Network Diversity (ND) was calculated using data from the Kinder, Lydenburg and Domini (KLD) database. The KLD measures firms on multiple stakeholder dimensions, which essentially equate to stakeholder constituencies. While traditionally these scores have been used to operationalize Corporate Social Responsibility/ Performance (Waddock \& Graves, 1997; Berman, Wicks, Kotha \& Jones, 1999; Orlitzky, Schmidt \& Rynes, 2003), in this paper we utilize them as measures of the 
level of firm's stakeholder engagement (i.e. the firm's ability to respond effectively to each stakeholder groups' demands).

Since Network Diversity prioritizes scope over size activity, we borrow a formula that is common in natural science research, the Shannon index (Shannon, 1948). While the application of the formula has normally been limited to estimating animal specie diversity, its precepts are valid for our specific purposes. The specific measure is as follows

$$
\begin{aligned}
& \begin{array}{c}
S \\
\text { Network Diversity }=-\Sigma p * \ln p
\end{array} \\
& \mathrm{i}=\mathbf{1} \\
& \text { where } \mathrm{p}=\mathrm{KLD} \text { dimension score/ Total KLD score }
\end{aligned}
$$

We focus on six KLD dimensions or stakeholder constituencies (community development, workplace diversity, employee relations, product safety/quality and stockholder/other). In the KLD database, each dimension is separated in two categories, strengths and weakness. For example on the Community involvement dimension there are six variables which attempt to measure the effectiveness of firm community involvement, as well as four variables that evaluate the firm's efforts at not addressing the concerns related to the community stakeholders. Conventionally, to calculate a KLD dimension score, the weaknesses of each dimension was subtracted from its corresponding strengths and these values were then aggregated. In this study a novel approach was implemented which treated the weakness variables on the KLD instruments as negatively worded items. Instead of subtracting the weaknesses from the strengths, the weaknesses items were reverse scored (since each item was binary scored $0 \mathrm{~s}$ become $1 \mathrm{~s}$ and vice versa) and then added to their corresponding strengths.

The decision to use this calculation was prompted by a need to eliminate negative numbers (because of the use of the Shannon index) and to salvage variance across the construct. Considering the KLD items used in this study were already binary scored, using the residual scores between strengths and weaknesses may further impinge upon the variance across the sample for this construct, and potentially deflate any significant relationships it may have with other constructs. Total KLD score was the aggregate of each individual dimension score.

Network Consistency (NC) The measure of Network Consistency (NC) uses the scores on the strengths and weakness on each KLD stakeholder dimension. Importantly, the emphasis of Network Consistency is to determine the level of variance in the firm's responsiveness/behavior across its stakeholder group relationships 
(i.e. stakeholder network). In order to derive this measure, the standard deviation among the firms score on the six stakeholder dimensions incorporated in the KLD was computed. As per the CSR measure, the weaknesses items were reverse scored and aggregated and then added to the corresponding strength for each dimension. The standard deviation across these six scores was then inverted to ensure that firms with higher consistency (i.e. lower standard deviations) were rewarded with higher Network Consistency.

This inverted standard deviation score, by itself, is insufficient since it does not discriminate between positive and negative consistency. Positive consistency occurs when firms treat each stakeholder group partner well and similarly. Negative consistency, alternatively, describes a situation where the firm treats its stakeholder partners similarly, but poorly. Since the influence of Network Consistency on Corporate Social Reputation is hypothesized to be positive, one does not expect negative Network Consistency to be instrumental to corporate reputation enhancement. In fact, negative Network Consistency is argued to detract from the level of reputational capital since it is likely to stir ill-will and negative stakeholder dispositions towards the firms.

Therefore, the valence of the firm's stakeholder relationships (positive or negative) must be accounted for in order to empirically reward firms that demonstrate high positive Network Consistency, and punish those that show high negative consistency. In order to incorporate valence directly into the measure of Network Consistency, a maximum possible score was calculated based on the number of KLD items for which data was available. There was data for fifty-six items (56) across these six dimensions, and since binary scoring was used, the maximum score for any firm was fifty-six (56). The average score for each firm was therefore twenty-eight (28). This average score was used to assign a valence sign (positive or negative) to the inverted standard deviation scores of the firms in the sample. Firms, for which the sum of their KLD stakeholder dimension scores (strengths + reverse scored weaknesses) was less than the 28 , were assigned a negative sign. Those with scores of twenty-eight and above remained positive.

Utilizing this approach, both the consistency of scores across stakeholder dimensions, as well as the magnitude of the firm's performance with respect to stakeholder treatment is explicitly considered and included in the measurement of the Network Consistency construct. 


\section{Firm Financial Performance (FP)}

In this study two base measures of Firm Financial Performance were used: Return on Assets (ROA) (measured as Income before extraordinary items/Total Assets) and Tobin's q (Market Value of the firm at end of fiscal year (MKVALF)/Book value of Total Assets). The former represents a conventional 'accounting' or internal measure of firm performance, while the latter is market oriented, and has been used as a valid measure of a firm's market value (Lee \& Grewal, 2004; Rao, Manoj $\&$ Dahlhoff, 2004). The firm's score on these principle measures was standardized based on industry average and standard deviation to derive the actual Firm Financial Performance score.

There are two reasons why we employed two measures for this construct. First, we acknowledge the debate pervading previous stakeholder research regarding the merits of both accounting and market-based measures of firm performance (McGuire, Sundgren \& Schneeweis, 1988). Second, because of the cognitive, intangible and 'environmentally-determined' nature of Corporate Reputation, we expect its relationship with Tobin's q to be stronger than that with ROA (Wood \& Jones, 1995; Orlitzky et al., 2003). Therefore using these two measures should allow for some meaningful comparison.

Finally, we controlled for firm size because of its established relationship and influence on financial performance (Wiggins \& Ruefli, 2002). This control variable was operationalized as the logarithm of number of employees.

\section{RESULTS}

Tables 1 and 2 illustrate, respectively, the descriptive statistics and correlation matrix for our measures. With respect to Table 1, the measures of skewness and kurtosis are a test of the normality of the data. For skewness, values $<-1$ or $>1$ indicate high skewness (Bulmer, 1979) while values $<-3$ or larger than 3 indicate high levels of kurtosis (since skewness for a normal distribution is 0 and kurtosis is 3 ). With respect to our constructs, Network Diversity, Network Consistency and Corporate Reputation were all within the range for both skewness and kurtosis. However, both our measures of financial performance, Tobin's q and ROA, are both substantially outside the desired limits (ROA in regards to kurtosis and Tobin's q for both skewness and kurtosis). This was relatively expected considering the volatile and sporadic nature of financial measures (Corrado \& Su, 1996). While transformations of data through logarithms or exponential manipulations (conventionally squaring values or taking their squared roots) can often effectively deal with non-normality, 
the nature of the data for both these constructs made these transformations impractical and/or impossible. Both ROA and Tobin's q included negative values in their data distribution, which eliminates the use of logarithm or square root transformation. Although the data could have been squared, because these values were measured relative to industry average, using absolute values would have compromised the ability to discern between high and low performers. Finally, while inversion transformation was attempted it did little to normalize the data and so the data for these constructs were left in their present state.

While recognizing the problematic nature of violating the non-normality assumption, especially for Tobin's q, we accepted these measures into the model based on the argument, that as sample size increases, the difference in power, (i.e. the model's ability to detect a 'true effect'), between a normal and non-normal distribution decreases (Jahan \& Kahn, 2012). Thus, because of our sample size, we do not expect significant underestimation, overestimation or misspecification of our results. Also, since outliers here are extreme actual values found in the tail of the distribution, and not from non-normal measurement error, then, the robustness of the regression is less compromised. Further, since both ROA and Tobin's q were standardized relative to the industry average, the influence of outliers is expected to less pronounced and troublesome.

\section{Table 1}

Descriptive Statistics

\begin{tabular}{|l|c|c|c|c|}
\hline & N & Mean & Skewness (Range) & Kurtosis (Range) \\
\hline Corporate Reputation & 790 & 6.50 & $(0.44)$ & 0.77 \\
Network Diversity & 790 & 0.18 & 0.80 & 0.63 \\
Network Consistency & 790 & $(0.51)$ & 0.94 & 0.17 \\
Financial Performance & 790 & 0.21 & 0.06 & 14.62 \\
(ROA) & & & 18.16 & 417.83 \\
$\begin{array}{l}\text { Financial Performance } \\
\text { (Tobin's q) }\end{array}$ & 790 & 0.14 & & \\
Firm Size & 790 & 1.57 & 0.03 & 0.56 \\
\hline
\end{tabular}

The correlations in Table 2 indicate that there are some significant correlations between constructs, which provide preliminary support for our hypothetical relationships. 
A multiple regression approach was employed to test our model. In the first equation (Regression 1) the two network constructs, Diversity and Consistency, were added as independent variables, regressed on the dependent variable Corporate Reputation. For the second equation, (Regression 2), Firm Financial Performance (ROA or Tobin q) becomes the dependent variable regressed against Corporate Reputation.

Table 2

Correlation Matrix

\begin{tabular}{|l|c|c|c|c|c|c|}
\hline & 1 & 2 & 3 & 4 & 5 & 6 \\
\hline 1) Corporate Reputation & 1 & & & & & \\
\hline 2) Network Diversity & 0.10 & 1 & & & & \\
\hline 3) Network Consistency & $0.11^{\star \star}$ & $0.12^{\star \star}$ & 1 & & & \\
\hline 4) ROA & $0.21^{\star \star}$ & $(0.01)$ & 0.00 & 1 & & \\
\hline 5) Tobin's q & $0.15^{\star \star}$ & 0.05 & 0.004 & $0.45^{\star \star}$ & 1 & \\
\hline 6) Firm Size & $0.07^{\star}$ & $0.12^{\star \star}$ & $(0.08)^{\star}$ & 0.00 & $(0.01)$ & 1 \\
\hline
\end{tabular}

* significant at $p=0.10,{ }^{\text {** }}$ significant at $p=0.05$

Table 3 provides these results, including regression coefficients and $\mathrm{F}$ values for the regression equations. Based on the results we do not find support for Hypothesis 1, that Network Diversity is positively related to Corporate Reputation. The coefficient is almost $0(-0.002)$ and not statistically significant. However the standardized beta coefficient for Network Consistency is both positive and significant $(0.11$, $\mathrm{p}<0.05$ ) thus supporting Hypothesis 2 . Hypothesis 3 , which purports that Corporate Reputation is positively related to Firm Financial Performance, is supported for both ROA $(0.211, \mathrm{p}<0.05)$ and Tobin's $\mathrm{q}(0.153, \mathrm{p}<0.05)$. This provides evidence that Corporate Reputation is a valuable resource to enhancing firm success. 
Table 3

Regression For Model 1

\begin{tabular}{|l|c|}
\hline $\begin{array}{l}\text { Dependent Variable = Corporate Reputa- } \\
\text { tion }\end{array}$ & $\begin{array}{l}\text { Standardized Beta Coefficient (only for } \\
\text { Independent Variables) }\end{array}$ \\
\hline Network Diversity & $(0.002)$ \\
\hline Network Consistency & $0.111^{\star \star}$ \\
\hline R & 0.111 \\
\hline Adjusted R sq & 0.01 \\
\hline F & $4.90^{\star \star}$ \\
\hline
\end{tabular}

${ }^{*}$ significant at $\mathrm{p}=0.10,{ }^{* *}$ significant at $\mathrm{p}=0.05$

To test Hypothesis 4 and 5 which argue that Network Diversity and Network Consistency positively moderate the relationship between Corporate Reputation and Firm Financial Performance, we create interaction terms by finding the product between the predictor (Corporate Reputation) and moderator (Network Diversity or Network Consistency) and through regression, identify the significance of the change in F scores as well as the strength and statistical significance of the interaction term in the hierarchical regression equation (Frazier et al. 2004; Baron \& Kenny, 1986).

Table 4 provides these results for both ROA and Tobin's q. In the case of ROA, the change in the F statistic after introducing the two interaction terms (NETDIVINT and NETCONINT) is not significant ( $\mathrm{F}$ change $=1.46, \mathrm{p}>0.05)$. Also, while both interaction terms are negative (NETDIVINT substantially so), neither is statistically significant. So both $\mathrm{H} 4$ and $\mathrm{H} 5$ are not supported for ROA. Using Tobin's q however provides us with some interesting, albeit unexpected results. The change in $\mathrm{F}$ value here is significant $(\mathrm{F}$ change $=4.33, \mathrm{p}<0.05)$ but this significance is driven primarily by the moderating effect of Network Diversity (NETDIVINT) which is significant, but highly negative $(-0.752, \mathrm{p}<0.05)$. Thus, as with ROA, the Tobin's $\mathrm{q}$ model does not lend support for $\mathrm{H} 4$ or $\mathrm{H} 5$, but potentially proposes a reverse moderating effect for Network Diversity. 
Table 4

Regression For Model 2

\begin{tabular}{|l|c|c|}
\hline Dependent Variable & ROA & Tobin's q \\
\hline Corporate Reputation & $0.630^{\star *}$ & $0.901^{\star \star}$ \\
\hline Network Diversity ${ }^{\star}$ Reputation & $(0.419)$ & $(0.0752)^{\star *}$ \\
\hline Network Consistency ${ }^{*}$ Reputation & $(0.026)$ & $(0.038)$ \\
\hline Firm Size & $(0.032)$ & $(0.037)$ \\
\hline$\Delta F$ & 1.46 & $4.33^{\star \star}$ \\
\hline
\end{tabular}

${ }^{*}$ significant at $\mathrm{p}=0.10,{ }^{* *}$ significant at $\mathrm{p}=0.05$

\section{$\overline{\text { DISCUSSION }}$}

This study is an attempt to identify the effect of stakeholder management on both Corporate Reputation and Firm Financial Performance and by so doing contributes to multiple streams of business literature. Some examples of these are:

\section{(a) Corporate Reputation}

With respect to CR research, our model introduces two network antecedents that are proposed to help to increase reputation stock, as well as protect this stock from competitor imitation. Much of the work on CR has focused on one or few stakeholder dimensions; customers (Carmeli \& Tishler, 2005), community (McGuire et al., 1988), financial investors (Srivastava et al., 1997), employees (Turban $\&$ Greening, 1997) or the natural environment (Russo \& Fouts, 1997). This myopic treatment, while simple and appealing, often ignores the complexity of CR. A network approach however, while acknowledging the independence of stakeholder relationships, also accounts for possible interdependencies between and among stakeholder constituencies, and the implications of these interdependencies to CR. Thus it does not sacrifice the macro for the micro or vice versa, but incorporates these levels simultaneously and complementarily.

While our findings suggest that Network Consistency enhances CR, the value of Network Diversity to CR is not clearly evident. One explanation for this result is that stakeholder multiplicity, identified earlier as a driver of Network Diversity, may ironically erode the benefits associated with diverse stakeholder engagement. As suggested previously, the benefit of increased Network Diversity is derived from the uniqueness of the reputational flow each new stakeholder constituency provides to the firm. However in an age of increased role multiplicity and information sharing, the potential uniqueness from enhanced Network Diversity might be more of 
a perception than a reality; therefore, the benefit of Network Diversity might be exaggerated.

\section{(b) Social Network Theory}

Social network theory has a rich legacy in business literature (Borgatti \& Foster, 2003; Brass et al., 2004). However, as Provan, Fish and Sydow (2007) note, much of the network research, especially in the organizational studies arena, actually ignore the network level of analysis in favor of the inter-organizational or intra-organizational level. To remedy this, they recommend greater utility of network level constructs such as network density, centrality, and multiplicity in contemporary network studies (Provan, Fish \& Sydow, 2007). Consistent with their recommendations, both network constructs discussed here, exist at the network level of analysis, suggesting that their existence and magnitude are dependent upon the state of the overall network rather than the properties of its individual parts.

\section{(c) Resource Based View (RBV)}

Finally, the study does offer some insight to RBV researchers, especially with respect to inimitability. While many drivers of inimitability, both internal and external, have been previously identified (Rumelt, 1984; Dierickx \& Cool, 1989; Barney, 1986; Barney, 1991; Mahoney \& Pandian, 1992), researchers still struggle to conceptualize and measure these drivers. Our stakeholder network approach might prove helpful to these endeavors by first arguing that networks themselves can be effective tools for resource inimitability and by further proposing that network properties, such as Network Diversity and Network Consistency, can be used as 'proxy' measures of inimitability.

Both Network Diversity and Network Consistency are expected to promote resource complexity, which in turn positively affects resource inimitability and ultimately firm financial performance. However, our results show that neither actually positively moderates the link between CR and Firm Financial Performance. While the effect of Network Consistency is negligible, the moderating effect of Network Diversity is highly negative. Although the latter finding is unexpected and initially counterintuitive, considered simultaneously with the lack of a relationship between Network Diversity and CR, this negative finding seems relatively understandable. Because there is little tangible reputational advantage from Network Diversity, there is little financial reward to offset the additional financial, informational and managerial resources expended on acquiring and sustaining these diverse relationships. Further, while the complexity of a diverse stakeholder network might be an obstacle to competitor imitation, in the short-term it may also impede the firm's ability to 
effectively manage its existing reputation. Thus the perceived pay-off isn't worth the potential pain

We conclude our discussion with a brief description of our empirical limitations. In an effort to be both transparent and balanced we identify some key issues that challenged our methodology and restricted our empirical analysis and ultimately, our findings.

\section{Limitations:}

Firstly, because of the longitudinal nature of the study, and its dependence on secondary data, there was a need to compromise between optimality and availability. Both the KLD and Fortune databases have been previously criticized for subjectivity, selectivity, content invalidity and financial bias (Mattingly \& Berman, 2006; Brown \& Perry, 1994; Luo \& Bhattcharya, 2006). These shortcomings notwithstanding, the databases offer large sample sizes and multiple years of data. Nevertheless, future efforts could be made to either minimize the biases within these measures, or create new instruments to more accurately measure the constructs used.

Secondly, because the sample is exclusively comprised of large U.S. public firms, questions about the generalizability of our results are warranted. While a more cosmopolitan and inclusive sample would have been preferred, the unavailability of data for either small and/or non-US firms made this unattainable.

Thirdly, much like the sample selection and measurement choices, the selected time period was somewhat determined by the availability of data. The chosen period, 1995-1999 is associated with general growth and prosperity in the US economy. Ironically, this economic health might affect the generalizability of the results, since critics may suggest that the financial welfare of US firms during this period fuelled CR, rather than the other way around. Increasing the tenure of years analyzed, as well as using more contemporary data, might assist in overcoming this limitation.

\section{CONCLUSION}

As scholars, we have accepted that the issues related to Corporate Reputation are vast and often complex. We have also acknowledged that in order for reputation research to be taken seriously as in the realm of strategy and management study, it must submit itself to the rigors of scientific inquiry.

This study, while in no means exhaustive, attempts to contribute to the evolution of this scientific inquiry by adopting a novel approach to CR management and empirically testing the benefits of this network treatment to both Corporate Reputation and Firm Financial Performance. Although, we do not find evidence here to 
equivocally support or denounce our model, or the strategic stakeholder benefits of the network approach, we strongly suggest that our findings motivate further and richer investigation. Finally, while it may possibly raise more questions than its answers, the study hopes to motivate research aimed at investigating the strategic implications and benefits of a network stakeholder approach.

\section{REFERENCES}

Barnett, M. (2007). Stakeholder influence capacity and the variability of financial returns to corporate social responsibility. Academy of Management Review, 32, 794-816.

Barney, J. B. (1991). Firm resources and sustained competitive advantage. Journal of Management, 17, 99-120.

Baron, R. M., \& Kenny, D. A. (1986). The moderator-mediator variable distinction in social psychological research: Conceptual, strategic and statistical considerations. Journal of Personality and Social Psychology, 51, 1173-1182.

Beggs, J.J., Haines, V.A. \& Hurlbert, J.S. (1996). Revisiting the rural-urban contrast: Personal networks in non-metropolitan and metropolitan settings. Rural Sociology, 2, 306-325.

Berman, S.L., Wicks, A.C., Kotha, S \& Jones, T.M. (1999). Does stakeholder orientation matter? The relationship between stakeholder management models and firm financial performance. Academy of Management Journal, 42, 488-506.

Black, J. A. \& Boal, K. (1994). Strategic resources: Traits, configurations and paths to sustainable competitive advantage. Strategic Management Journal, 15, 131148.

Borgatti, S.P. \& Foster, P.C. (2003). The network paradigm in organizational research: A review and typology. Journal of Management, 29, 991-1013.

Brass, D.J., Galaskiewicz, J., Greve, H.R. \& Tsai, W. (2004). Taking stock of networks and organizations: A multilevel perspective. Academy of Management Journal, 47, 795-817.

Bromley, D. (2000). Psychological aspects of corporate identity, image and reputation. Corporate Reputation Review, 3, 240-252.

Bronn, C. \& Bronn, P.S. (2005). Reputation and organizational efficiency: A data envelopment analysis study. Corporate Reputation Review, 8, 45-58.

Brown, B. \& Perry, S. (1995). Halo-removed residuals of Fortune's responsibility to the community and environment: A decade of data. Business \& Society, 34, 199-215. 
Brown, T.J. \& Dacin, P.A. (1997). The company and the product: Corporate associations and consumer product responses. Journal of Marketing, 61, 68-84.

Bulmer, M. (1979). Principle of statistics. Dover, New York

Carmeli, A. \& Tishler, A. (2005). Perceived organizational reputation and organizational performance: An empirical investigation of industrial enterprises. Corporate Reputation Review, 8, 13-30.

Corrado, C.J., \& Su, T. (1996). Skewness and kurtosis in S\&P 500 Index returns implied by option prices. Journal of Financial Research, 19, 175-92.

Davies, G., Chun, R., Da Silva, R.V. \& Roper, S. (2003). Corporate Reputation and Competitiveness. London and New York: Routledge.

Dierickx, I. \& Cool, K. (1989). Asset stock accumulation and sustainability of competitive advantage. Management Science, 35, 1504-1511.

Eisenhardt, K. M. \& Martin, J. A. (2000). Dynamic capabilities: What are they? Strategic Management Journal, 21, 1105-1121.

Fombrun, C. \& Shanley, M. (1990). What's in a name? Reputation building and corporate strategy. Academy of Management Journal, 33, 233-258.

Fombrun, C., Gardberg, N. \& Barnett, M. (2000). Opportunity platforms and safety nets: Corporate citizenship and reputational risk. Business and Society Review, 105, 85-106.

Fombrun, C.J. (1996). Reputation: Realizing value from the corporate image. Harvard Business School Press, Boston, MA.

Frazier, P. A., Tix, A. P. \& Barron, K. E. (2004). Testing moderator and mediator effects in counseling psychology research. Journal of Counseling Psychology, $51,115-134$.

Granovetter, M. (1973). The strength of weak ties. American Journal of Sociology, 78, 1360-1380.

Granovetter, M. (1992). Problems of explanation in economic sociology. In Nohria, N., Eccles, R.G. (Eds.), Networks and organization: structure, form, and action, 22-56. HBS Press: Boston.

Gulati, R. \& Gargiulo, M., (1999). Where do inter-organizational networks come from? American Journal of Sociology, March, 177-231.

Hart, S.L. (1995). A Natural-resource-based- view of the firm. Academy of Management Review, 20, 986-1014.

Helfat, C. E. \& Peteraf, M. A. (2003). The dynamic resource-based view: Capability lifecycles. Strategic Management Journal, 24, 997-1010. 
Hillman, A. J. \& Keim, G. D. (2001). Shareholder value, stockholder management and social issues: What's the bottom line? Strategic Management Journal, 22, 125-139.

Hutton, J.G., Goodman, M.B., Alexander, J.B. \& Genest, C.M. (2001). Reputation management: the new face of corporate public relations? Public Relations Review, 27, 247-261.

Jahan, S. \& Khan, A. (2012). Power of t-test for simple linear regression model with non-normal error distribution. Journal of Scientific Research, 4, 609-622.

Kostova, T. \& Roth, K. (2003). Social capital in multinational corporations and a micro-macro model of its formation. Academy of Management Review, 28, 297317.

Lee, R. \& Grewal, R. (2004). Strategic responses to new technologies and their impact on firm performance. Journal of Marketing, 68, 157-171.

Lewis, S. (2003). Reputation and corporate social responsibility. Journal of Communication Management, 7, 356-365.

Luo, X. \& Bhattacharya, C.B. (2006). Corporate social responsibility, customer satisfaction, and market value. Journal of Marketing, 70, 1-18.

MacMillan, K., Money, K., Downing, S. \& Hillenbrand, C. (2004). Reputation in relationships: Measuring experiences, emotions and behaviors. Corporate Reputation Review, 8, 214-233.

Mahoney, J.T. \& Pandian, J.R. (1992). The resource-based view within the conversation of strategic management. Strategic Management Journal, 13, 363-380.

Mattingly, J.E. \& Berman, S. (2006). Measurement of corporate social action: Discovering taxonomy in the Kinder, Lydenburg, Domini (KLD) Ratings Data. Business and Society Review, 45, 1-27.

McGuire, J. B., Sundgren, A. \& Schneeweis, T. (1988). Corporate social responsibility and firm financial performance. Academy of Management Journal, 31, 854-872.

Money, K. \& Hillenbrand, C. (2006). Beyond reputation measurement: Placing reputation within a model of value creation by integrating existing measures into a theoretical framework. Working paper presented at the $10^{\text {th }}$ Annual conference on Corporate Reputation, Image and Competitiveness

Nelson, R. R. \& Winter, S. G. (1982). An Evolutionary Theory of Economic Change. Cambridge, MA: Harvard University Press.

Neville, B.A., Bell, S.J. \& Menguc, B. (2005). Corporate reputation, stakeholders and the social performance-financial performance relationship. European Journal of Marketing, 39, 1184-1198. 
Orlitzky, M., Schmidt, F. \& Rynes, S. (2003). Corporate social and financial performance: A meta analysis. Organization Studies, 24, 403-441.

Porter, M.E. (1985). Comparative advantage. New York: The Free Press.

Porter, M.E. (1996). What is strategy? Harvard Business Review, Boston, MA.

Provan K.G., Fish A. \& Sydow J. (2007). Inter-organizational networks at the network level: A review of the empirical literature on whole networks. Journal of Management, 33, 479-516.

Rao, V., Manoj, K.A. \& Dahlhoff, D. (2004). How is manifest branding strategy related to the intangible value of a corporation? Journal of Marketing, 68, 126141.

Roberts, P.W. \& Dowling, G.R. (2002). Corporate reputation and sustained superior financial performance. Strategic Management Journal, 23, 1077-1093.

Rumelt, R. (1984). Towards a strategic theory of the firm. In R. Lamb (Ed.), Competitive Strategic Management, 556-570, Englewood Cliffs, NJ: Prentice Hall.

Russo M.V. \& Fouts P.A. (1997). A resource-based perspective on corporate environmental performance and profitability. Academy of Management Journal, 40, 534-559.

Sanchez, J. L., \& Sotorrio, L. (2007.) The creation of value through corporate reputation. Journal of Business Ethics, 76, 335-346.

Shannon, C.E. (1948). A mathematical theory of communication. Bell System Technical Journal, 27, 379-423 and 623-656.

Shapiro, C. (1983). Premiums for high quality products as returns to reputations. Quarterly Journal of Economics, 98, 659-679.

Srivastava, R., McInish, T., Wood, R. \& Capraro, A. (1997). The value of corporate reputation: Evidence from equity markets. Corporate Reputation Review, 1, 6267.

Stanwick, P. A. \& Stanwick, S.D. (1998). The relationship between corporate social performance and organizational size, financial performance, and environmental performance: An empirical examination. Journal of Business Ethics, 17, $195-$ 204.

Turban, D. B. \& Greening, D. W. (1997). Corporate social performance and organizational attractiveness to prospective employees. Academy of Management Journal, 40, 658-672.

US SIF Report (2012). http://www.ussif.org/files/Publications/12_Trends_Exec_ Summary.pdf

Waddock, S.A. \& Graves, S. (1997). The corporate social performance-financial performance link. Strategic Management Journal, 18, 303-317. 
Walsh, G., Dinnie, K.J. and Weidmann, K.P. (2006). How do corporate reputation and customer satisfaction impact customer defection? A study of private energy customers in Germany. Journal of Services Marketing, 20, 412-420.

Weiss, A.M., Anderson, E. \& MacInnis, D.J. (1999). Reputation management as a motivation for sales structure decisions. Journal of Marketing, 63, 74-89.

Whetten, D.A. \& Mackey, A. (2002). A social actor conception of organizational identity and its implications for the study of organizational reputation. Business \& Society, 41, 393-414.

Wood, D. J., \& Jones, R. E. (1995). Stakeholder mismatching: A theoretical problem in empirical research on corporate social performance. International Journal of Organizational Analysis, 3, 229-267.

Yoon, E., Guffey, H. \& Kijewski, V. (1993). The effects of information and company reputation on intentions to buy a business service. Journal of Business Research, 27, 215-228.

\section{BIOGRAPHICAL SKETCH OF AUTHORS}

Dr. Richard Peters is an Assistant Professor of Management at Xavier University of Louisiana. He currently teaches at the Undergraduate level in the Division of Business. His research interests are in Corporate Social Responsibility and Sustainability (CSRS) and International CSRS Pedagogy, with a recent emphasis on emerging markets. He has published articles in the International Journal of Management and Enterprise Development and Journal of Management and Organization (forthcoming) and has presented at numerous national and regional conferences. $\mathrm{He}$ holds a Ph.D. from Florida Atlantic University

Dr. Peggy Golden is a Professor of Management and chair of the Management Department at Florida Atlantic University. She has been published in many leading journals including European Management Journal, Strategic Management Journal and Journal of International Marketing. Her present work is related to knowledge, capabilities and Corporate Social Responsibility. She holds a Ph.D. in Strategic Management, from the University of Kentucky. 